\title{
Sustainability Transition in Established Corporations: Role of Technological Innovation
}

\author{
Rahul Patil ${ }^{1}$, Akriti Jain², Anjula Gurtoo ${ }^{3}$ \\ Paper presented at \\ Sixth Biennial Conference of the Indian Academy of Management (INDAM) - 2020, \\ At IIM-Tiruchirappalli, India \\ On \\ 1-4 January 2020 \\ Acknowledgement: This study is part of a wider project called IPACST ${ }^{4}$ supported by \\ the Belmont Forum and NORFACE Joint Research Programme on Transformations to
} Sustainability.

\begin{abstract}
Sustainability transition theories analyze a systematic shift towards sustainability at micro (niche), meso (regime) and macro (landscape) level. The assessment of technological systems and structures at the firm level in sustainability transition literature is scant. The present study, taking the technological assessment perspective at the firm level, finds answers to questions like (a) how do established corporations move towards sustainable practices? (b) what role does technological innovation play in the firm's transition towards sustainability? (c) what technological modes get adopted for sustainability transition? We find answers to these questions through an in-depth case analysis of two multi-national companies in the consumer goods industry. Internally developed and externally acquired technologies by firms in the last 15 years are plotted using qualitative and quantitative indicators on pre-designed templates. Technologies for all three sustainability dimensions, namely, environmental, social and economic, get mapped and the impact assessed. The analysis finds a sustainability transition landscape reflecting the use of protected (patents, trademarks, designs) and unprotected technologies (open innovation) to generate impacts like production efficiency, consumption reduction, emission reduction, reduce-recycle-reuse among others. Companies implementing sustainable technologies do observe positive impacts. Implementation of reduce-reuserecycle (3R)-based technologies enhance the achievement of sustainable development targets. Furthermore, the use of trademarks seems common in differentiating their technologies and identities. The last section uses these and other results to comment on the role of managing intellectual property and harnessing the effect of technological innovations in sustainability transition.
\end{abstract}

Keywords: Sustainability transitions; Transition management; technological innovation

\footnotetext{
1 Project Associate, Centre for Society and Policy, Indian Institute of Science, Bangalore 2 Postdoctoral Fellow, Centre for Society and Policy, Indian Institute of Science, Bangalore

3 Professor, and Chair, Centre for Society and Policy, Indian Institute of Science, Bangalore

4 https://ip4sustainability.org/
} 
Introduction

Environmental problems like resource depletion, energy supply, climate change, Green House Gas (GHG) emission have gained prominence not only in political agenda but also in business strategies (Geels, 2010; Jorgensen, 2012). Businesses, realizing their responsibility towards sustainability, not only use technology and strategic interventions to bring about sustainability but also transform their value chain and market system in which they operate (Loorbach and Wijsman, 2013). New environmental problems emerged during the 1990s differ in complexity and scale as compared to problems like local water pollution and air pollution (Geels, 2010). The former call for change in socio- technical systems i.e. changes not only in technologies but also in culture, institutions, consumer behaviour, market structure, infrastructure, policy regime among others to move towards sustainability.

Sustainability transition refers to the dynamic process of change in a socio-technical system that takes place at niches (micro), regime (meso) and landscape (macro) levels (Geels, 2002; Jorgensen, 2012). Existing 'technological regime' refers to the boundary within which businesses/industry undergo technological progress through incremental innovation along predefined trajectories (Nelson and Winter, 1977). The existing regime as a set of rules, regulations, governing the structure, elements and forces create inertia due to path dependence and lock-ins. Such inertia can be broken either by the emergence of the new regime (transition), promotion of niche level activities (experimentation for radical innovations) or by landscape pressure (society and cultural changes) (Kemp et al., 1998).

Prominent theories of sustainability transition i.e. Technological Innovation System (TIS) (Carlsson and Stankiewicz, 1991), Strategic Niche Management (SNM) (Kemp et al., 1998), Multi-Level Perspective (MLP) (Rip and Kemp, 1998; Geels, 2002) and Transition Management (TM) (Loorbach et al., 2009) theories analyse dynamics of sustainability transition at any one or all three levels. TIS, at the meso level, emphasizes on innovation system performance by looking at the systematic interplay between firms under a given institutional infrastructure (Markard et al., 2012). SNM focuses on creating space or niches through public policies to promote networking and learning among actors and stakeholders (Schot and Geels, 2008). SNM potentially transforms an environmentally unsustainable regime (Kemp et al., 1998). MLP looks at the dynamics of the interplay between niche, regime and landscape to understand the evolution of sustainable pathways. TM, on the other hand, looks at the interaction between actor and the environment and advocates four types of activities to govern transition management. These are strategic, tactical, operational and reflexive activity.

Prior literature on sustainability transition largely focusses on system or meso level context (Bai et al., 2009; Tàbara and Ilhan, 2008). Firm or actor-oriented perspective to understand the role of technological innovation and strategic alliance in sustainability transition has received limited attention in the extant literature (Farla et al., 2012; Markard and Truffer, 2013; Sarasini and Linder, 2018), Addressing the issues we undertake firm-level analysis, based on TM approach, to analyze activities, systems and governance undertaken by firms to move towards sustainability. In addition, we also explore the role of technology, Intellectual Property (IP) and strategic interventions in the sustainability transition. We conduct an in-depth case analysis of two multi-national companies in the consumer goods industry and track their environmental, social and economic impact over time. Such impacts get captured through qualitative and quantitative indicators on pre-designed templates to create a sustainability impact landscape. 


\section{Methodology}

The case studies aim to identify the role of technological and intellectual property innovations in sustainability transitions. These analyses follows a step methodology, namely, identification of company employing sustainable practices, extracting sustainability impact data from various sources, plotting impact data versus sustainability indicators versus technology/strategic/IP interventions on pre-designed templates, analyzing and interpreting obtained maps, and detailing the role of technological innovation.

Companies with sustainable practices get identified based on prima facie observation such as the adoption of environment-friendly technology, nomination or receiving sustainability recognition, etc. Further companies get selected based on a detailed survey of sustainability reports, business responsibility reports, dedicated web portals for sustainability reporting, etc. Companies following GRI standards may be given preferences.

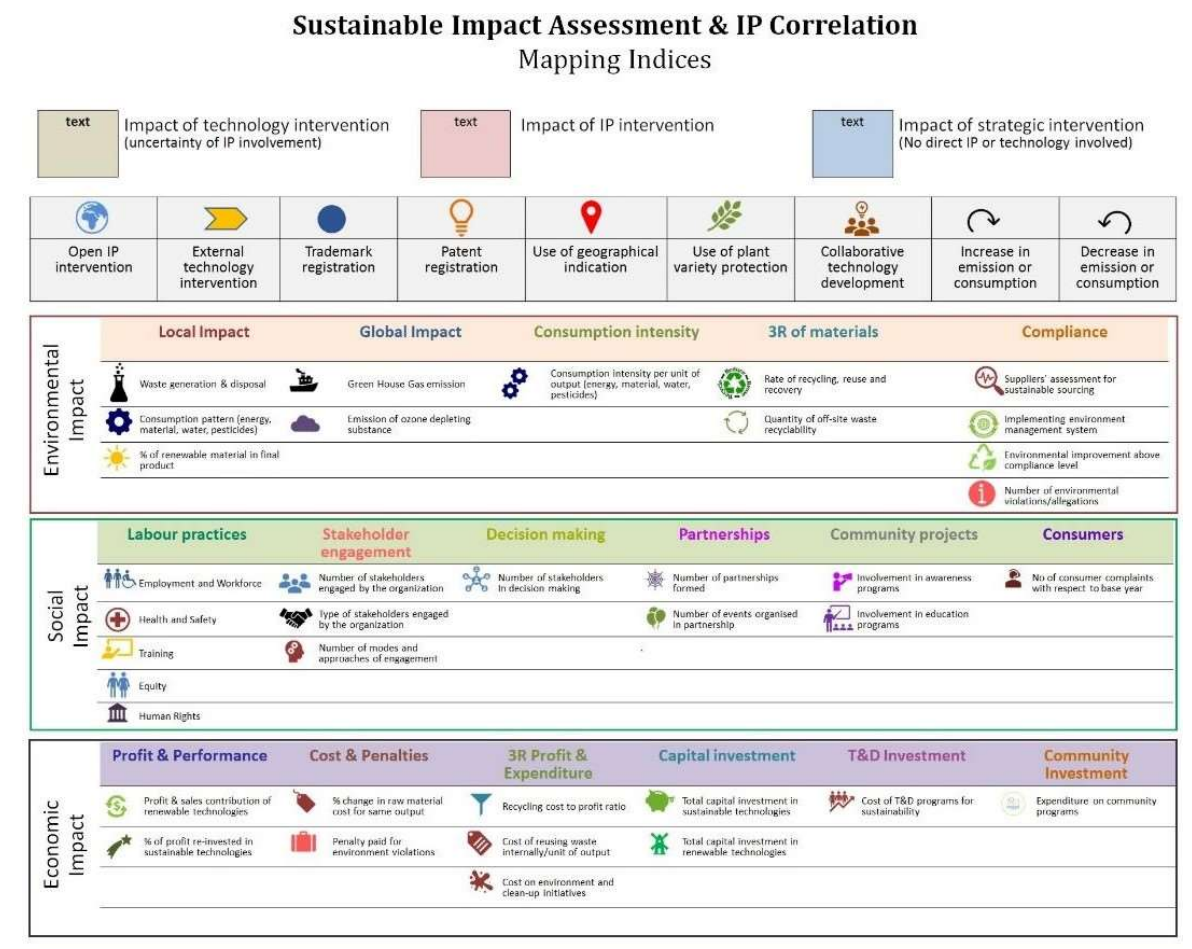

Figure 1: Indicators and variables categories with identifiers useful for quick analysis of impact data from impact sub-templates

Sustainability data can be recovered in qualitative and quantitative formats. For plotting the data, pre-designed sustainability impact assessment templates can be used. These templates have 24 high importance indicators (HIMs) representing various sustainable business models (refer to Figure 1). These further involve three sub-templates, each assigned to environment, social and economic impact mapping, for each selected case company (e.g. Figure 2). Each sub-template consists of indicators in the first column and corresponding variables in the second column. The first row provides space for plotting of technology, intellectual property and strategic interventions. A range of identifiers facilitate quicker identification of impacts during analysis. The remaining matrix plots impact data in respective sub-templates. Linkages between interventions and their impact can be linked to each other by coloured arrows. 
Detailed plotting of impacts against various indicators across three sub-templates (see figure 3) provides an insightful picture of the strengths and weaknesses of companies in achieving sustainability impact. Environmental impact assessment sub-template captures local impact, global impact, consumption intensity, reduce-reuse-recycle (3R) impact, compliance and voluntary actions. Social impact assessment sub-template captures impact data related to employment, health and safety, training, equity and human rights, stakeholder engagements, partnership for sustainability practices, community involvement, and workforce/consumers' satisfaction. Economic impact assessment sub-template captures impact data related to profit, costs, and penalties from sustainable activities, investments in $3 R$ processes, training and sustainable community projects (refer figure 1 ).

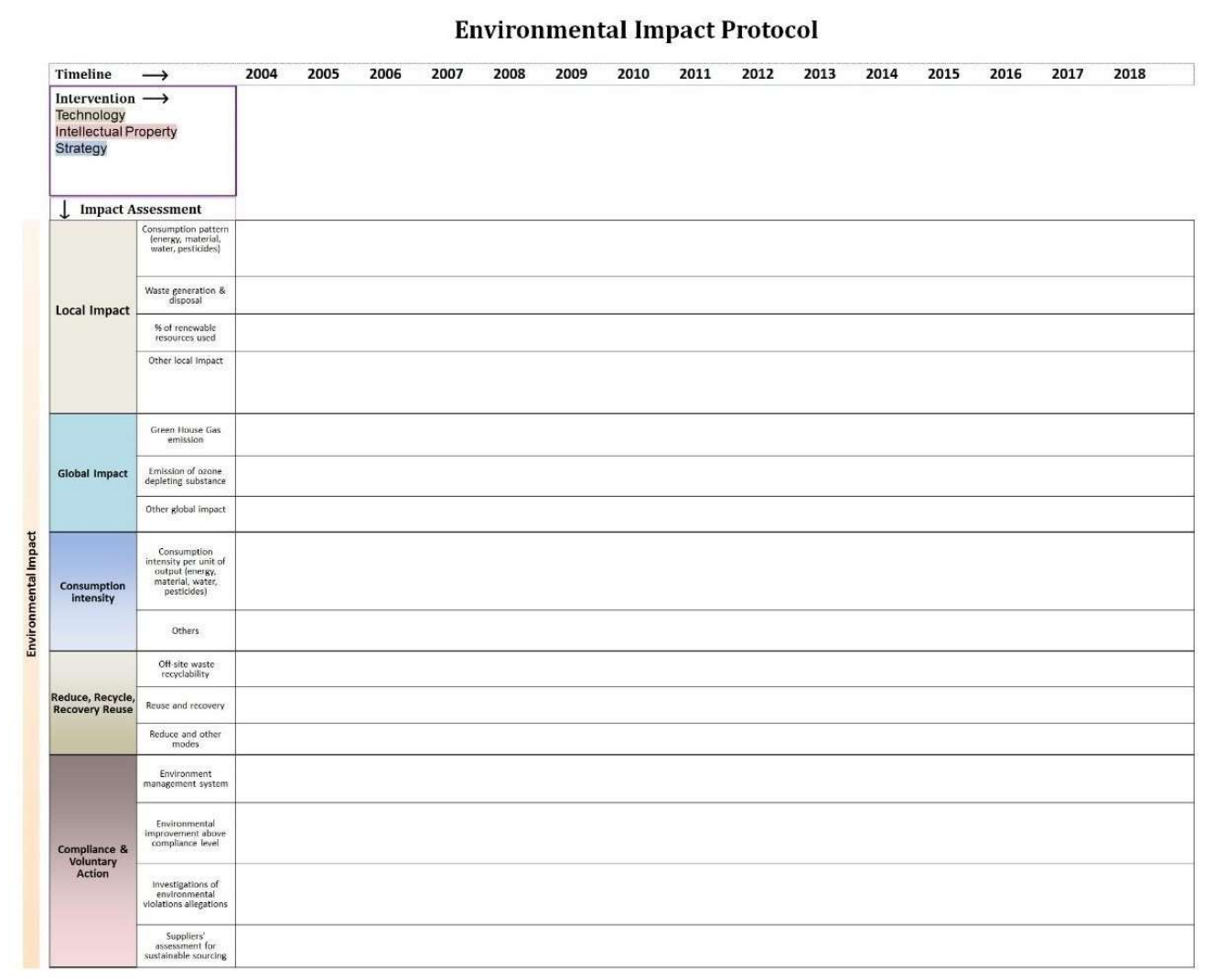

Figure 2: Sustainable impact assessment protocols (sub-templates) for plotting of impact data versus sustainability indicators versus technology/strategic/IP interventions

\section{Results \& Analysis}

\section{Cases: Role of firms' interventions in sustainability transitions}

Selected companies represent the fast-moving consumer goods industry, and are almost a century old, well-established corporation. Hindustan Unilever Limited's (HUL) global variant existed since the late 1920s whereas Coca-cola incorporated in late 1880s. In the Indian marketplace, HUL has a presence since the 1930s whereas Coca-cola has intermittent presence since 1950s to 1970s and resuming operation since 1993. Exploring the role of various interventions across these companies over a period of 15 years has the potential to back the findings with strength. The analysis involved mapping of strategic, technological and intellectual property interventions against achieved environmental, social 
and economic impact through implementation thereof. We, further, classified activities carried out by said companies programmed under these interventions into three sets of spheres namely strategic, tactical, and operational as conceptualized by Loorbach (2007) in a transition management theory.

Both HUL and Coca-cola set an example of accelerating the sustainable transition by executing transition management approaches. Effective implementation of a range of interventions makes them forerunner in modifying supply chain, redesigning products and processes, rebranding of an image, and improving consumers' perception. Mainly these organizations focused on marking environmental and social impact. Reporting of economic impact seems to be less pronounced. Environmental aspects were explored through predetermined local, global, compliance, philanthropic, 3R-based indicators. Social aspects mapping revolves around employment and training, health and safety, equity and human rights, community partnerships and stakeholder engagements, and consumer satisfaction. Lesser reporting is observed regarding investments, profits, costs and penalties during a sustainability transition.

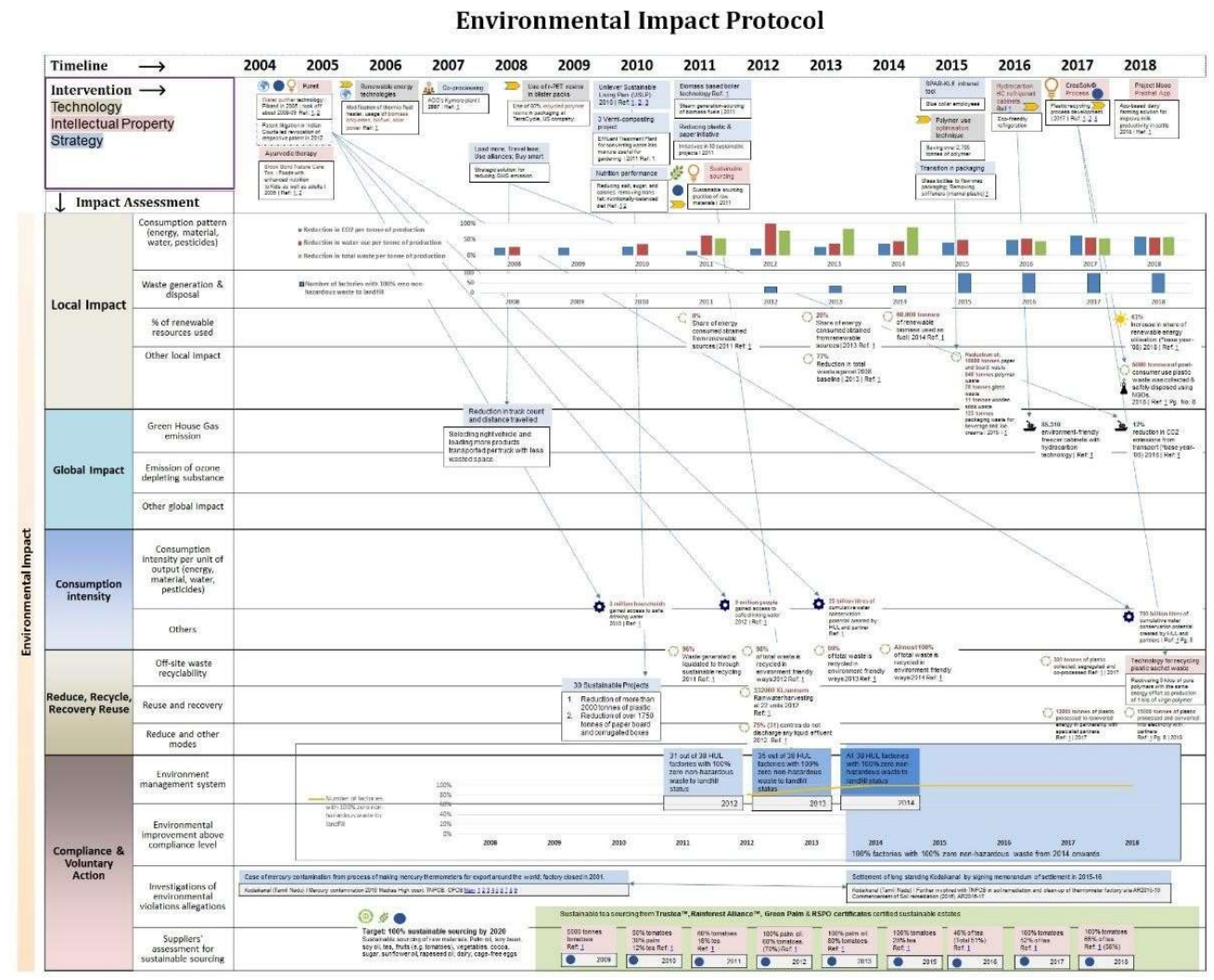

Figure 3: Plot of the environmental impact of sustainable technologies and practices adopted by Hindustan Unilever Limited (HUL) over 15 Years

\subsection{Strategic activities:}

Strategic activities involve developing vision, goals, long-term strategies and norms. Both companies HUL and Coca-cola identified a need for corporate responsibilities towards sustainability since the very beginning but formalized strategic action plans very recently e.g., HUL's Unilever Sustainable Living Plan (USLP) 2010. Formalizing such action plans helped these corporations in achieving their objectives aggressively. These strategies are 
planned in alignment with UN Sustainable Development Goals delivering betterment of business and betterment of the world with hand in hand. HUL repurposes the value chain in making sustainable living commonplace. Largely they plant protocols for improving health and wellbeing (SDGs 2, 3 and 6), reducing environmental footprints (SDGs 7, 12-15), and enhancing livelihoods (SDGs 1, 3-5, 8 and 10). They decided to extract values from their natural, financial, and intangible resources. They have set ambitious 10 - year and 20-year goals across range of pillars such as reducing greenhouse gas impact of all the products to half until 2030, reducing the water associated with consumer use of all products to half by 2020 , reducing the waste after disposal of products to half $2020,100 \%$ sustainable sourcing of agricultural raw materials by 2020 , reaching out a billion people for improved health, hygiene and nutrition by 2020 , creating fairness at workplace, opportunities for women, and promoting inclusive business by involving smallholder farmers, small-scale retailers, and young entrepreneurs. Coca-cola sets goal to deliver on the issues of sustainable sourcing (SDGs 1, 4, 5, 8, 10, 12, and 17), climate protection, packaging and recycling (SDGs 11-13, and 17), human and workplace rights, women's empowerment (SDGs 5), water stewardship (SDGs 6, 12 and 14). Coca-cola has committed for $100 \%$ sustainable sourcing, reducing carbon-footprints of the drinks by $25 \%$ by 2020 , donating $1 \%$ of operating income to Cocacola foundation \& company donations, making of $100 \%$ recycling packaging by 2025 , use of at least $50 \%$ recycled material in packaging by 2030 , use of freshwater and replenishment, and empowering 5 million women economically by 2020 . Overall, we see the strategic settings helped the organization in widening their scope of responsibilities from mandatory corporate social responsibility (CSR) activities to more pronounced modifications in a sustainable value chain.

\subsection{Tactical activities:}

Tactical activities aim at commissioning supportive networks or alliances and setting of short-term programs. Such networking and programming led corporations closer to inclusive business objectives. Through these activities corporations formed alliances and empowered their research capabilities, and unleashed the power of farmers, women, young entrepreneurs, suppliers, retailers, consumers, and employees. They formed networks with farmers with smallholdings for sustainable sourcing, networking with women by creating opportunities in the retail value chain, dealing with consumers for reaching out with more nutritional and healthy products, and allowing nurturing environments to employees or their right to participate in unions. As an example, HUL involved in empowering women through programs called Shakti Entrepreneurs for incorporating women in their retail value chain which simultaneously strengthens their retail business arms. On the other hand, Coca-cola involved in the 5 by20 program for empowering women entrepreneurs with the help of partners such as UN Women, Bill and Melinda Gates Foundation, MercyCorps, etc. Sustainable sourcing of agricultural raw material forms another example where both corporations took interest. These practices follow the Sustainable Agricultural Guiding Practices (SAGP). These practices ensure farming with responsibility, standard human and workplace rights, and environmental protection.

\subsection{Operational activities:}

Operational activities focus on developing and implementing new technologies, innovations, practices, or products. HUL and Coca-cola have also developed various technologies and 
practices to bring their highly ambitious goals to ground reality. As an example, to deal with plastic packaging and related issues, corporations came up with $3 \mathrm{R}$ technologies which focus on reduce, reuse, and recycle principles. HUL co-developed CreaSolv ${ }^{\circledR}$ process with the German Fraunhofer Institute for Process Engineering and Packaging IVV. They found inspiration from inventions of recycling TV sets for developing the process. They started using r-PET plastic resins, which are $80 \%$ recycled PET, in the blister packs for personal care products. Optimizing polymer use in industrial processes results in reduced resources utilization. They follow transition in packaging where glass bottles get replaced by flow wrap packaging, removing stiffeners and internal plastics, and promoting the use of refill pouches among customers. Coca-cola has also developed a process for PET bottle recycling and promote the use of plastic bottles formed from plant-based renewable sources in their beverage bottles. They share the technology with other industries like Ford Motors where the technology gets used for developing fabric interior of Fusion Energi hybrid sedan. These corporations increase internal efficiency by adopting various technologies based on renewable energy such as modified thermic fluid heaters, use of biomass briquettes, biofuels, solar power, steam generation using biomass fuels, etc. Companies follow various innovative initiatives such as sharing of eco- friendly hydrocarbon refrigerant cabinets with retailers and suppliers, sharing of specially developed dairy farming app Project Mooo for farmers useful in improving milk productivity in cattle, development of SPAR-KLE intranet tool for company's blue-collar employees with monitoring and rewarding benefits, etc.

\subsection{Reflexive activities and sustainable impact assessment:}

All three strategic, tactic and operational activities are performed over decades and need monitoring, assessment and evaluations to track the transition towards sustainability. Companies implement monitoring programs to track the performance of these activities. Such programs can be categorized under the reflexive sphere. These can potentially play a role in streamlining of working protocols during sustainability transformation.

Monitoring and assessment of strategic, tactical and operational activities suggest sustainability impacts remained more pronounced in environmental and social aspects. Figure 2 shows an example of the environmental impact assessment of technological and IP interventions and strategic practices for HUL over 15 years. The complete environmental, social, and economic analyses of both HUL and Coca-cola can be found in Annexure 1.

Both the organization have managed to reduce their $\mathrm{CO}_{2}$ emission, water usage, total waste generation per tonne of productions. Both firms try to tackle plastic waste using technologies as well as tactical practices. HUL maintains the tag of 'zero non-hazardous waste to landfill' consecutively for all the Indian factories with since 2015 . Specially designed sustainable technologies such as Pureit of HUL and PlantBottle technologies have been incorporated in the value chain. By 2018, HUL's Pureit water purification technology provided 89 billion litres of safe drinking water and Coca cola's PlantBottle technology PlantBottle has avoided the $\mathrm{CO}_{2}$ emissions equivalent of taking nearly 1 million vehicles off the road since 2009 . As part of strategic initiatives, HUL's Hindustan Unilever Foundation and Coca cola's Anandana Foundation are involved in various teaching and training, resource conservation, and social development. 


\section{Role of technological, strategic and intellectual property interventions in sustainability transition}

These two case studies highlight the potential of tactical practices and technology interventions to deliver ambitious goals and make them a reality. Along with this, case studies also demonstrate both companies handling intellectual property in a peculiar way. Both the companies rely on protected as well as unprotected forms of technologies. Trademarks protections get used heavily by both corporations.

Formation of alliances forms one of the important tactical practices adopted by these companies. HUL partnered with Fraunhofer Institute for Process Engineering and Packaging IVV in Germany in co-development of CreaSolv ${ }^{\circledR}$ Process which recycles sachet waste. The technology forms the core technology in achieving the goal of making $100 \%$ packaging recyclable by 2025. HUL has tackled the use of waste in an innovative way through partnership. In 2007, HUL tried to use expired personal care products (waste) in ACC's Kymore cement plant for co-processing. They hauled 137000 tonnes of such waste as an alternative fuel and raw materials to recover energy or material value from them. In 5 years, HUL's wastage has replaced $0.3 \%$ of the total heat requirement at ACC's plant. Unilever, HUL's parent company has partnered with TerraCycle and launched $100 \%$ recycled PET (rPET) bottles. The model of tactical alliances suggests companies enhance their technological capabilities through partnerships that support achieving sustainability goals aggressively. This underlines the importance of tactical alliances in sustainability transitions.

These corporations have also tried to incorporate intellectual property interventions in achieving social sustainability by moderating environmental practices. Coca-cola India conceptualized a program Fruit Economy where company procures oranges from Nagpur, Maharashtra, an area known for geographical indication tag to orange. The process aims at sustainable sourcing of fruits with optimal use of resources such as water, fertilizers, pesticides, etc. To accelerate the sustainability transition, Coca-cola further implemented Ultra HighDensity Plantation (UHDP) technique and partnered with Jain Irrigation to adopt their (IP protected) Drip Irrigation Technology. UHDP techniques boost agricultural yield per acre within a time span whereas Drip Irrigation technology reduces water consumption in agriculture. In this type of IP model, Coca-cola used internally developed technologies, externally developed patent-protected technology, used geographical indication tags for sourcing of fruits from local communities, and used various trademark protected certification programs for differentiating farmers adopting sustainable practices from others. Adoption of the model accelerated sustainability transition by sustainable sourcing practices (tactics) and use of (patented) drip irrigation technologies. These interventions optimized consumption patterns of resourcesand empowered farmers from local communities (identified through geographical indication tags) which adopted sustainable practices (identified using trademarked certificates). Also, through this selective approach, enhanced productivity of farm products particularly benefited farmers in enriching their economic position. HUL has also taken steps, on similar lines, in sustainable sourcing of various plant products where they use a range of certifications like Trustea ${ }^{\mathrm{TM}}$, Rainforest Alliances $^{\mathrm{TM}}$, Green Palm ${ }^{\mathrm{TM}}$ and RSPO ${ }^{\mathrm{TM}}$ Certificates.

In another model, these companies utilize their in-house skills and develop technology on their own. HUL came up with Pureit water purifier and Coca-cola unveiled their PlantBottle technology for preparation of $100 \%$ recyclable plastic obtained from renewable plant-based materials. These have found to be impactful as Pureit has delivered so far 89 billion litres of safe drinking water whereas PlantBottle technology has saved equivalent annual emissions of more than 315000 metric tons of carbon dioxide. 
In yet another model, Coca-cola seems to be extracting extra potential from their flagship PlantBottle technology. The technology helps in developing fully recyclable PET plastic made up of entirely renewable materials. The tetcnology uses the patent-protected process for converting sugarcane and waste from the sugar manufacturing process. Since the first launch of the original PlantBottle Coca-cola improved the technology continuously and launched $100 \%$ PlantBottle. Within 2009-15, more than 40 billion PlantBottle packages have reached the market in over 40 countries preventing 365,000 metric tons of potential $\mathrm{CO}_{2}$ emissions. Besides the use of the technology for the company, Coca-cola initiated to leverage the potential of the patent-protected technology by licensing to other industries. In 2011, The Coca-cola company licensed PlantBottle Technology to $\mathrm{H}$. J. Heinz for use in ketchup bottles. In 2013, Ford Motor Company announced the use of the packaging technique in the fabric interior of the Fusion Energi hybrid sedan. In 2014, the first reusable, fully recyclable plastic cups made with PlantBottle technology were marketed in SeaWorld $®$ and Busch Gardens ${ }^{\circledR}$ theme parks across the United States of America. The model pronounces the positive impact of patent protection on this sustainable technology in promoting sustainability transition.

Another interesting use of IP by these companies incorporate marketing perspective and brand creation. They potentially create value for their brands by projecting the benefits of these sustainable technologies to the consumers. Coca-cola builds emotional connections with consumers and differentiated themselves from others by trademarking their technology. On the other hand, HUL reaches out to the consumers through corporate social responsibility initiatives to introduce sustainable behaviors, teachings, training, nutrition, health, safety, etc. However, all such initiatives get incorporated under HUL foundation's various arms identified with (trademark protected) brand names of HUL's sustainable products e.g., promoting handwashing habits (under Lifebuoy's brand) in people useful for reducing diarrhea and respiratory diseases. The outreach of the handwashing program under CSR activity reportedly reached 1.3 million people in 2018. Similarly, HUL partnered with Water Health International (WHI) in 2017 under Pureit's brand and set up four community water plants near Bangalore providing drinking water INR 8-10 per 20 litres. Through this, HUL manages to strengthen the penetration of its sustainable brands.

These companies, further, explore the use of potentially unprotected technologies such as the thermic fluid heater, biomass briquettes, biofuel, vermicomposting, steam generation using biomass fuels, etc. Such technologies get applied for optimizing industrial processes, reducing waste, internally. In such case, corporations enhance internal sustainability by reducing environmental footprint using potentially open IP or not-necessarily IP protected technology.

\section{Conclusion}

Companies do intervene in developing and implementing technologies, intellectual properties, and strategies to accelerate the sustainability transition. Technology interventions may include redesigning products and processes, changing resource types and consumption, incorporating renewable sources-based technologies, etc. IP interventions may include patent protection to specially developed technologies internally or in collaboration, effective use of trademarks, geographical indications, and trade secrets. Whereas, these interventions form part of larger umbrella setting ambitious, long-term sustainability goals such as achieving $100 \%$ sustainable sourcing, modifying supply chains with sustainable practices, reducing resource use and wastage, maintaining gender balance and human rights, empowering women, collaborating with NGOs and social enterprises, diverting CSR funds towards social and environmental well-being, etc. Use of alliances remains an important tool used by corporations at various stages of developing technology, sourcing raw materials, and managing/disposing of post-selling waste. Collaborating with various stakeholders in the rural 
economy may lead to strong economic impact at the grass-root level. Along with implementing operational activating, reflexive, monitoring, \& reporting activities form an important part of managing sustainability transition. Economic impacts remain underreported as compared to environmental and social impacts achieved through various initiatives taken up by corporations.

Companies not established with sustainable practices and technologies reorient themselves. Companies protect state-of-the-art technologies with patenting and try to extract value through various modes such as internal use or licensing out. They have extensively used trademarks for differentiating sustainable technologies from other market players. Mostly technology and IP interventions by corporations focus on environmental as well as economic aspects, whereas adopting tactical practices through effective strategic interventions may balance all the three sustainability aspects namely, environmental, social and economic.

\section{References}

Baia, X., Wieczorek, A.J., Kaneko, S., Lisson, S., Contreras, A. (2009). Enabling sustainability transitions in Asia: The importance of vertical and horizontal linkages. Technological Forecasting and Social Change, 76(2), 255-266.

Carlsson, B., \& Stankiewicz, R. (1991). On the nature, function and composition of technological systems. Journal of evolutionary economics, 1(2), 93-118.

Farla, J., Markard, J., Raven, R., Coenen, L. (2012). Sustainability transitions in the making: A closer look at actors, strategies and resources. Technological Forecasting \& Social Change 79 (2012) 991-998.

Geels, F.W., 2002. Technological transitions as evolutionary reconfiguration processes: a multi-level perspective and a case-study. Research Policy 31, 1257-1274.

Geels, F. W. (2010). Ontologies, socio-technical transitions (to sustainability), and the multilevel perspective. Research policy, 39(4), 495-510.

Kemp R. (1994) Technology and the transition to environmental sustainability: the problem of technological regime shifts. Futures, 26(10), 1023-1046.

Kemp, R., Schot, J., Hoogma, R. (2007) Regime shifts to sustainability through processes of niche formation: The approach of strategic niche management. Technology Analysis \& Strategic Management, 10(2), 175-198.

Kemp, R., Schot, J., Hoogma, R. (1998). Regime shifts to sustainability through processes of niche formation: the approach of strategic niche management. Technology Analysis \& Strategic Management 10, 175-195.

Loorbach, D., Wijsman, K. (2012). Business transition management: exploring a new role for business in sustainability transitions. Journal of Cleaner Production, 45, 20-28.

Loorbach, D., Bakel, J.C.V., Whiteman, G., Rotmans, J. (2009) Business Strategies for Transitions Towards Sustainable Systems. Business Strategy and the Environment, DOI: $10.1002 / \mathrm{bse}$

Markard, J., Ravenn, R., Truffer, B. (2012) Sustainability transitions: An emerging field of research and its prospects. Research Policy, 41, 955-967. 
Markard, J. \& Truffer, B. (2008) Actor-oriented analysis of innovation systems: exploring micro-meso level linkages in the case of stationary fuel cells, Technology Analysis \& Strategic Management, 20(4), 443-464.

Markard, J., Raven, R., \& Truffer, B. (2012). Sustainability transitions: An emerging field of research and its prospects. Research policy, 41(6), 955-967.

Nelson, R.R., Winter, S.G. (1977). In search of useful theory of innovation. Research Policy 6, 36-76.

Sarasini, S., \& Linder, M. (2018). Integrating a business model perspective into transition theory: The example of new mobility services. Environmental innovation and societal transitions, 27, 16-31.

Tàbara, J.D., Ilhan, A. (2008). Culture as trigger for sustainability transition in the water domain: the case of the Spanish water policy and the Ebro river basin. Reg Environ Change (2008) 8: 59. 